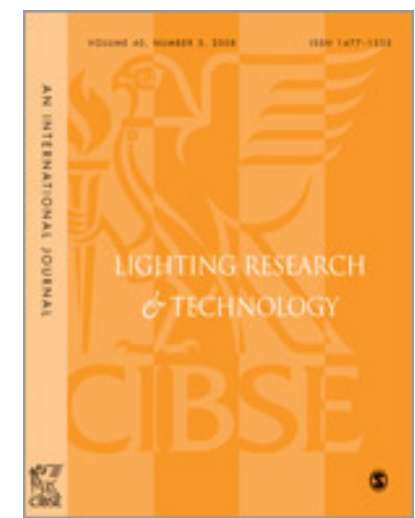

\title{
The Role of Lighting in Road Traffic Collisions
}

\begin{tabular}{|c|c|}
\hline Journal: & Lighting Research \& Technology \\
\hline Manuscript ID & Draft \\
\hline Manuscript Type: & Original Manuscript \\
\hline $\begin{array}{r}\text { Date Submitted by the } \\
\text { Author: }\end{array}$ & $\mathrm{n} / \mathrm{a}$ \\
\hline Complete List of Authors: & $\begin{array}{l}\text { Raynham, Peter; UCL, Institute for Environmental Design and } \\
\text { Engineering } \\
\text { Unwin, Jemima; UCL, Institute for Environmental Design and Engineering } \\
\text { Khazova, Marina; Public Health England } \\
\text { Tolia, Sofia; UCL, Institute for Environmental Design and Engineering }\end{array}$ \\
\hline Keywords: & Road Lighting, Road Traffic Collisions, Daylight \\
\hline Abstract: & $\begin{array}{l}\text { The paper reports a study that examines how to determine if a road } \\
\text { traffic collision took place in daylight or in the dark. An innovative } \\
\text { method was developed, based on solar altitude, to establish cut off } \\
\text { points of daylight and darkness determined from a study of daylight } \\
\text { availability in England and Scotland. This approach provides a rigorous } \\
\text { method to differentiate the daytime and night time collisions. The criteria } \\
\text { were used in a study of the collisions reported in the STATS19 dataset } \\
\text { for the weeks either side of the clock changes that are necessary } \\
\text { between Greenwich Mean Time and British Summer Time. By comparing } \\
\text { periods with the same clock time either side of the time change, using } \\
\text { the aforementioned method, it was possible to isolate collisions within } \\
\text { the same time period that during one week occurred in darkness and in } \\
\text { the other week in daylight. The initial finding was that there are } 19.3 \% \\
\text { more collisions in the dark periods and there is an even greater increase } \\
\text { ( } 31.7 \% \text { ) in pedestrian injuries. }\end{array}$ \\
\hline
\end{tabular}

\section{SCHOLARONE" Manuscripts}




\title{
The Role of Lighting in Road Traffic Collisions
}

\begin{abstract}
The paper reports a study that examines how to determine if a road traffic collision took place in daylight or in the dark. An innovative method was developed, based on solar altitude, to establish cut off points of daylight and darkness determined from a study of daylight availability in England and Scotland. This approach provides a rigorous method to differentiate the daytime and night time collisions. The criteria were used in a study of the collisions reported in the STATS19 dataset for the weeks either side of the clock changes that are necessary between Greenwich Mean Time and British Summer Time. By comparing periods with the same clock time either side of the time change, using the aforementioned method, it was possible to isolate collisions within the same time period that during one week occurred in darkness and in the other week in daylight. The initial finding was that there are $19.3 \%$ more collisions in the dark periods and there is an even greater increase $(31.7 \%)$ in pedestrian injuries.
\end{abstract}

\section{Introduction}

It has long been argued that road lighting can reduce road traffic collisions ${ }^{1}$. However, studies in this area tend to treat road traffic collisions as a homogenous collection of incidents and thus provide little information on how to improve road lighting to reduce collisions ${ }^{2}$. Clearly lighting may have an impact in a collision when a driver does not see a hazard in the road at night, but it will be a less important factor in a collision that occurs due to a mechanical failure.

The causation and consequences of road traffic collisions are complex as there are many contributory factors in which light may play a role. However, due to the complex nature of the interactions it is difficult to isolate those collisions where lighting is the primary cause. Consider a driver pulling out of a side road on to a major high-speed road without checking if there was any traffic coming. It could be argued that better lighting conditions may have made it more likely that he would have noticed any traffic; however, the act of pulling out without due care does not cause a collision in the absence of traffic. Thus, the probability of a collision happening is also a function of traffic density. Figure 1 shows traffic density based on data collected and published by the Institution of Lighting Professionals (ILP) ${ }^{3}$ for England. The ILP data set was for 164 locations and a total of 2,452 days involving a total of 34,619,159 vehicle movements. Out of the 164 locations, 98 were within Essex and of the 2,452 days of data, 1,262 were from Essex, 980 from Northern Ireland with 210 days of data from the rest of the UK. Dates varied between 7 days of information per site up to 70 days' worth. The average number of vehicle movements for each hour of the day is presented as a percentage of the total traffic flow for a whole day. 
During the night there is a much-reduced traffic flow, so the chances of a collision may be reduced. However, as the road is less congested it is possible that the speed of vehicles may be higher ${ }^{\mathrm{i}}$ and so if a collision occurs it may be more severe. A further problem is that the way reported collision and casualty data is captured may also be a function of the daylight available. Consider a minor collision where a person has been in a vehicle and has been shaken slightly. During the daytime a paramedic attending the scene may well be able to assess that the person has no significant injuries; however, at night that assessment will be harder and acting on the precautionary principle, it may be decided that the person needs to go to hospital to be checked ${ }^{\text {ii }}$. This decision to send someone to hospital is likely to change the recorded severity of the collision. Given the above considerations, it is difficult to compare collision rates for different times of day and, thus, establish patterns of collisions associated with light and dark.

One approach to the problem has been to examine the weeks either side of the clock change that happens twice each year with the introduction and removal of daylight saving time. The advantage of this approach is that it permits the comparison of collisions during particular time windows, in pairs of similar weeks where one week the period is dark and the other week it is light. This approach has been used by Ferguson et al ${ }^{4}$ and also by Uttley and Fotios ${ }^{5}$ and a number of other studies, for example, Sullivan and Flanagan ${ }^{6}$. These studies compared recorded collisions that took place when it was nominally light in one week and it was nominally dark at the same time in the other week, with Ferguson et al categorising a period of one hour as twilight. The problem with most previous studies is the way of assessing when it is light and when it is dark. Ferguson et al based their limit of the light period at solar altitude $0^{\circ}$ and then treated the period of one hour with

\footnotetext{
${ }^{\mathrm{i}}$ It is a fundamental principal of highway design that traffic speed is a function of the ratio of traffic flow to the design capacity of the road. For further details see for example: DBRB Volume 13 Economic Assessment of Road Schemes Section 1 The COBA Manual Part 5 Speed on Links (COBA). Available at:

https://webarchive.nationalarchives.gov.uk/+/http:/www.dft.gov.uk/pgr/economics/software/coba1 1usermanual/part0the appofthecoba3152.pdf

ii The relationship between light colour and quantity clinical diagnosis is complex, however, poor lighting has the potential to reduce diagnostic confidence. See P A Lovett, M B Halstead, A R Hill, D A Palmer, T S Sonnex \& M R Pointer, The effect on clinical judgements of new types of fluorescent lamp: I Experimental arrangements and clinical results. Lighting Res. Technol 23(1) 35-51 (1991)
} 
the sun just below the horizon as being twilight. The work of Uttley and Fotios used the point at which the solar altitude was $0^{\circ}$ to mark the boundary between light and dark.

Clearly, during the transition between light and dark it would be reasonable to expect that the rate of collisions may change. Both Ferguson et al, and Uttley and Fotios found significant changes in collisions; however, without an accurate definition of when it is dark and when it is light it is not possible to study the recorded collisions in order to identify what types of incidents are more common in the dark. The objective of this paper is to investigate methods of isolating collisions that happen after dark and perform an initial examination of the record of traffic collisions for England, Scotland and Wales using a proposed new quantitative method.

It should be noted that the approach of this paper is to seek conditions that can be defined either as light or as dark. However, between these 2 conditions there is a period of twilight. During twilight, conditions gradually change from natural to artificial lighting or visa versa. The relationship between vehicle lights and daylight on the road was studied by Andre et $\mathrm{al}^{7}$ and they used the concept of a twilight illuminance of $3.3 \mathrm{~lx}$ as criteria for vehicle head lamp performance. However, the complex nature of lighting conditions during twilight means that for the sake of simplicity a study of collisions during twilight is not included in this report, as the paper focuses purely on light and dark conditions.

\section{Collision Data}

The STATS $19^{8}$ data set gives information on road traffic collisions that have taken place in England, Scotland and Wales. For this paper data for the years 2005 to 2015 have been studied, in which there are a total of 1,780,653 recorded collisions involving 3,262,270 vehicles which caused $2,402,909$ casualties. One of the fields in the data set provides the lighting condition at the time of the collision. There are several options that may appear in the field including Daylight or Darkness with a number of variations covering the presence or not of street lighting. If this field gives accurate information, then it could be used to determine which collisions took place after dark.

To check the accuracy of values in this field, the solar altitude all of collisions in the STAT19 dataset were calculated using the $\mathrm{NOAA}^{9}$ method. The collisions were checked to see if they had taken place when solar altitude was in the range $-8.5^{\circ}$ to $+5.5^{\circ}$ and 253,755 were found within the range. This range was selected on the basis that it was expected to include the whole of the transition between light and dark. It was expected that solar altitude would be a good predictor of daylight availability, and the probability of a collision being reported as taking place in daylight would be a function of solar altitude at the time of the collision. The results of this analysis are plotted in Figure 2 with separate columns for the morning and afternoon results. If the lighting condition field was accurate, the column heights at each solar altitude would be approximately the same. However, the analysis showed that this is not the case and it seems that the afternoon data lags the morning data by about $5^{\circ}$ of solar altitude. A potential explanation of this is that in many cases the daylight condition reported is not for the time of the collision but for some time afterwards, in the morning this means that solar altitude had increased before arrival and in the afternoon the sun would be setting, by the time the Police Officer arrived at the scene. Further analysis of the data was carried out and it was found that difference between morning and afternoon daylight probability was slightly less if a Police Officer did not attend the scene. 


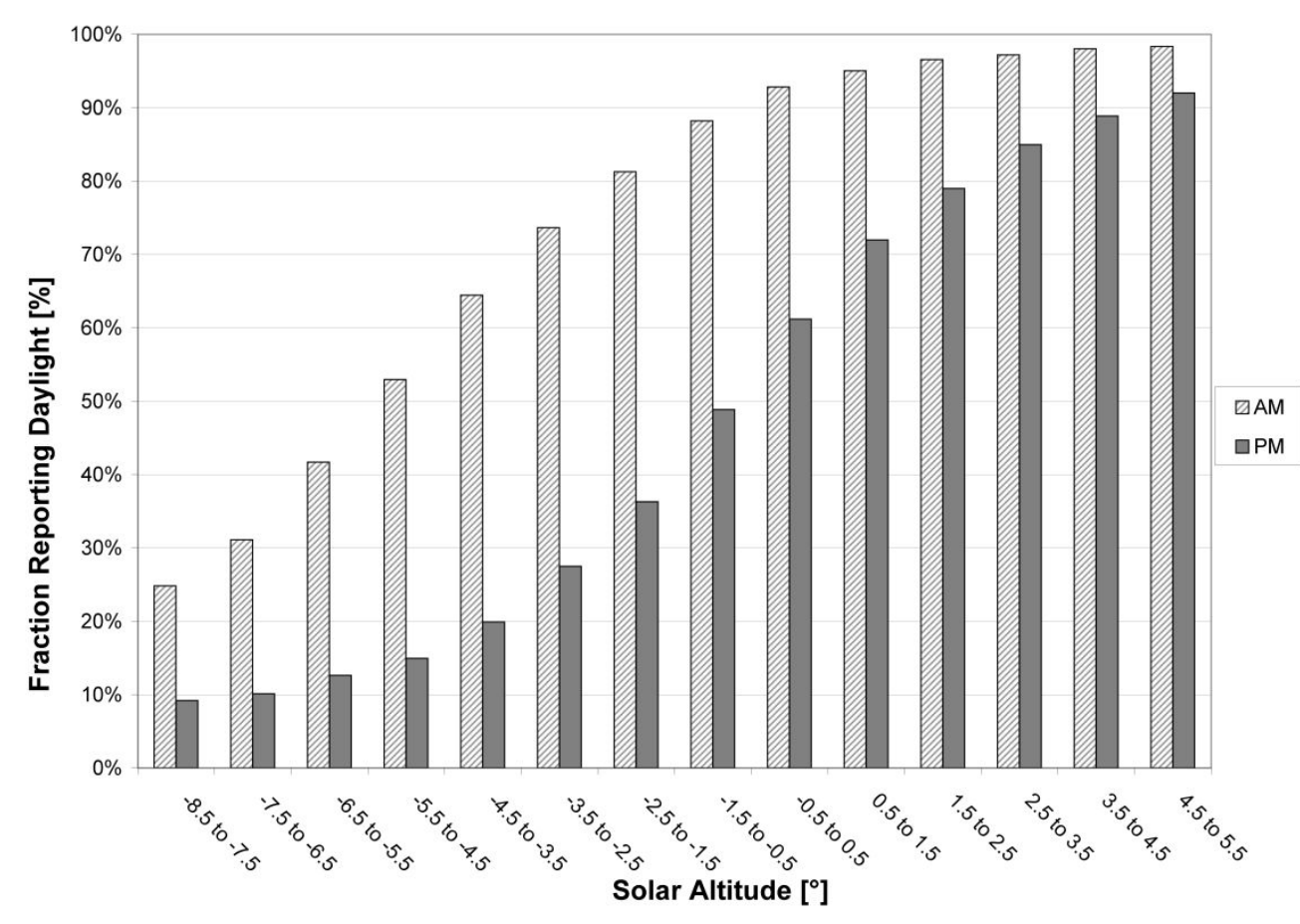

Figure 2 Percentage of collisions reported as daylit for varying solar altitude

This analysis shows that it is not possible to rely on the lighting condition field in the STATS19 dataset.

\section{Daylight Availability and Solar Altitude}

As mentioned in the previous section, it is expected that solar altitude would be a good predictor of daylight availability. To investigate this point, the daylight availability data set from Public Health England (PHE) was used. PHE run solar monitoring network ${ }^{10}$ stations around the UK and for this study we used illuminance data for the years 2015 and 2016 from the 8 PHE sites in England, Wales and Scotland. The locations used are listed in Table 1.

\begin{tabular}{|l|c|c|}
\hline Location & Latitude & Longitude \\
\hline Camborne & 50.2185 & -5.3271 \\
\hline Chilton & 51.5750 & -1.3180 \\
\hline Glasgow & 55.8625 & -4.3447 \\
\hline Inverness & 57.4734 & -4.1939 \\
\hline Leeds & 53.8451 & -1.6146 \\
\hline Lerwick & 60.1390 & -1.1848 \\
\hline London & 51.4988 & -0.1183 \\
\hline Swansea & 51.6094 & -3.9849 \\
\hline
\end{tabular}

Table 1 Locations of the data collection points

PHE records the average external illuminance for 5-minute intervals thus the section of data studied had over 1,600,000 records of illuminance. The resolution of the measurements is $0.01 \mathrm{klx}(10 \mathrm{~lx})$. The measuring equipment at the sites, with the exception of Lerwick, are mounted on the roofs of buildings, to ensure that as far as possible the sensors have an un-obscured view of the sky. In the dataset for the 8 locations over 2 years there were 19,270 illuminance values within the solar altitude range of $-8.5^{\circ}$ to $+2.5^{\circ}$. The calculation of solar altitude used the NOAA method using the time at the middle of the 5-minute interval over which the illuminance was averaged. To study daylight availability as function of solar altitude in the given range, the results were binned into $1^{\circ}$ 
intervals and the average illuminance and a range of percentiles for each bin were calculated. The results of this analysis are shown in Table 2.

\begin{tabular}{|c|c|c|c|c|c|c|c|c|c|c|c|c|}
\hline \multicolumn{2}{|c|}{ Solar Altitude Bin } & $-8^{\circ}$ & $-7^{\circ}$ & $-6^{\circ}$ & $-5^{\circ}$ & $-4^{\circ}$ & $-3^{\circ}$ & $-2^{\circ}$ & $-1^{\circ}$ & $0^{\circ}$ & $1^{\circ}$ & $2^{\circ}$ \\
\hline \multicolumn{2}{|c|}{ Lower Angle } & $-8.5^{\circ}$ & $-7.5^{\circ}$ & $-6.5^{\circ}$ & $-5.5^{\circ}$ & $-4.5^{\circ}$ & $-3.5^{\circ}$ & $-2.5^{\circ}$ & $-1.5^{\circ}$ & $-0.5^{\circ}$ & $0.5^{\circ}$ & $1.5^{\circ}$ \\
\hline \multicolumn{2}{|c|}{ Upper Angle } & $-7.5^{\circ}$ & $-6.5^{\circ}$ & $-5.5^{\circ}$ & $-4.5^{\circ}$ & $-3.5^{\circ}$ & $-2.5^{\circ}$ & $-1.5^{\circ}$ & $-0.5^{\circ}$ & $0.5^{\circ}$ & $1.5^{\circ}$ & $2.5^{\circ}$ \\
\hline \multicolumn{2}{|c|}{ Av Illuminance [Ix] } & 0.70 & 1.03 & 2.33 & 7.04 & 21.98 & 62.14 & 145.4 & 289.4 & 508.7 & 812.1 & 1216 \\
\hline \multirow{5}{*}{ 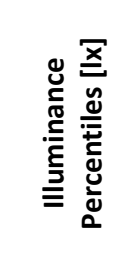 } & $1 \%$ & 0 & 0 & 0 & 0 & 0 & 0 & 10 & 20 & 50 & 80 & 130 \\
\hline & $10 \%$ & 0 & 0 & 0 & 0 & 0 & 10 & 40 & 80 & 140 & 230 & 350 \\
\hline & $50 \%$ & 0 & 0 & 0 & 0 & 20 & 50 & 120 & 260 & 460 & 760 & 1160 \\
\hline & $90 \%$ & 0 & 0 & 10 & 10 & 40 & 120 & 270 & 530 & 920 & 1450 & 2120 \\
\hline & $99 \%$ & 10 & 10 & 10 & 40 & 100 & 240 & 470 & 850 & 1380 & 2070 & 3002 \\
\hline
\end{tabular}

Table 2 Illuminance values at different solar altitudes

\section{Selection of Criteria for Light and Dark}

Based on the values in Table 2 for the analysis of road traffic collisions it would be reasonable to assume that it is dark at solar altitudes of $-6^{\circ}$ and below. At these low solar altitudes, the illuminance will be less than or equal to $10 \mathrm{~lx}$ more than $99 \%$ of the time and thus any street lighting present should have been switched on and the luminance of the road would be less than 0.3 $\mathrm{cd} \mathrm{m}^{\text {-2iii }}$. The choice of $-6^{\circ}$ as a starting point for darkness ties into the existing notion that the period of Civil Twilight stops at this point as well.

It is debatable which value of solar altitude to take as the start of reliable daylight on the road. Arguments could be made for the altitudes $0^{\circ}$ or $1^{\circ}$. At $0^{\circ}$ the illuminance is below $50 \mathrm{~lx}$ less than $1 \%$ of the time and this value rises to $80 \mathrm{~lx}$ at $1^{\circ}$. At both of these illuminance levels it would be normal for street lighting to be switched off; both values are higher than the illuminance at less than $1 \%$ of the time at below $-6^{\circ}$. For simplicity, a $0^{\circ}$ of solar elevation was used for the lower limit of the condition termed light. This choice aligns with the value used by most previous studies. See Table 3 for a summary of the choices made.

\begin{tabular}{|c|c|}
\hline Light Condition & Altitude \\
\hline Light & Above $0^{\circ}$ \\
\hline Dark & Below $-6^{\circ}$ \\
\hline
\end{tabular}

Table 3 Lighting Conditions in Relation to Solar Altitude

To confirm that $-6^{\circ}$ and $0^{\circ}$ boundaries for dark and light were valid, each site was then checked individually to find that the top one percentile value of the $-6^{\circ}$ bin for all sites was $101 \mathrm{x}$, except for Swansea where $10 \mathrm{~lx}$ occurred at the top third percentile. Likewise, percentile data were extracted from the bottom percentile of the $0^{\circ}$ bin for all sites and found all values to be above or equal to 50 $1 \mathrm{x}$, except for Swansea, where $50 \mathrm{~lx}$ occurred at the second percentile. The full list of values mentioned above, by city, can be found in Table 4 .

\footnotetext{
iii The $0.3 \mathrm{cdm}^{-2}$ assumes the use of a $\mathrm{Q}_{0}$, the bulk reflection factor for the road surface, of 0.1 which is higher than average for the UK.
} 


\begin{tabular}{|c|c|c|c|c|c|}
\hline \multirow[b]{2}{*}{ City } & \multicolumn{3}{|c|}{$-6^{\circ}$ bin percentiles } & \multicolumn{2}{|c|}{$0^{\circ}$ bin percentiles } \\
\hline & $97^{\text {th } *}$ & $98^{\text {th }}$ & $99^{\text {th }}$ & $1^{\text {st }}$ & $2^{\text {nd } * *}$ \\
\hline Camborne & $10 \mathrm{~lx}$ & $10 \mathrm{~lx}$ & $10 \mathrm{~lx}$ & $50 \mathrm{~lx}$ & $68 \mathrm{~lx}$ \\
\hline Chilton & $10 \mathrm{~lx}$ & $10 \mathrm{~lx}$ & $10 \mathrm{~lx}$ & $60 \mathrm{~lx}$ & $80 \mathrm{~lx}$ \\
\hline Glasgow & $10 \mathrm{~lx}$ & $10 \mathrm{~lx}$ & $10 \mathrm{~lx}$ & $50 \mathrm{~lx}$ & $60 \mathrm{~lx}$ \\
\hline Inverness & $01 \mathrm{~lx}$ & $10 \mathrm{~lx}$ & $10 \mathrm{~lx}$ & $60 \mathrm{~lx}$ & $80 \mathrm{~lx}$ \\
\hline Leeds & $10 \mathrm{~lx}$ & $10 \mathrm{~lx}$ & $10 \mathrm{~lx}$ & $50 \mathrm{~lx}$ & $70 \mathrm{~lx}$ \\
\hline Lerwick & $10 \mathrm{~lx}$ & $10 \mathrm{~lx}$ & $10 \mathrm{~lx}$ & $50 \mathrm{~lx}$ & $70 \mathrm{~lx}$ \\
\hline London & $10 \mathrm{~lx}$ & $10 \mathrm{~lx}$ & $10 \mathrm{~lx}$ & $70 \mathrm{~lx}$ & $81 \mathrm{~lx}$ \\
\hline Swansea & $10 \mathrm{~lx}$ & $20 \mathrm{~lx}$ & $20 \mathrm{~lx}$ & $30 \mathrm{~lx}$ & $50 \mathrm{~lx}$ \\
\hline$*$ & \multicolumn{5}{|c|}{ Note all illuminance values are $\leq 10 \mathrm{~lx}$. } \\
\hline$* *$ & \multicolumn{5}{|c|}{ Note all illuminance values are $\geq 50 \mathrm{~lx}$. } \\
\hline
\end{tabular}

Table 4 Comparison of city illuminance by threshold solar altitude bin.

Most previous studies have not used definitions for light and dark based on a study of available daylight illuminance. The study of daylight availability above suggests that Ferguson et $\mathrm{al}^{3}$ may have included significant periods of darkness in the twilight category.

\section{Initial Analysis of Collisions in Weeks Either Side of the Clock Change}

The weeks for which collisions were studied are given in Table 5. The dates are in four groups, before and after the spring change and before and after the autumn change. The actual clock change takes place at 01:00 AM on Sunday mornings (the first date in after columns).

\begin{tabular}{|cc|cc|cc|cc|}
\hline \multicolumn{2}{|c|}{ Spring Before } & \multicolumn{2}{c|}{ Spring After } & \multicolumn{2}{c|}{ Autumn Before } & \multicolumn{2}{c|}{ Autumn After } \\
Start & End & Start & End & Start & End & Start & End \\
$20 / 03 / 05$ & $26 / 03 / 05$ & $27 / 03 / 05$ & $02 / 04 / 05$ & $23 / 10 / 05$ & $29 / 10 / 05$ & $30 / 10 / 05$ & $05 / 11 / 05$ \\
$19 / 03 / 06$ & $25 / 03 / 06$ & $26 / 03 / 06$ & $01 / 04 / 06$ & $22 / 10 / 06$ & $28 / 10 / 06$ & $29 / 10 / 06$ & $04 / 11 / 06$ \\
$18 / 03 / 07$ & $24 / 03 / 07$ & $25 / 03 / 07$ & $31 / 03 / 07$ & $21 / 10 / 07$ & $27 / 10 / 07$ & $28 / 10 / 07$ & $03 / 11 / 07$ \\
$23 / 03 / 08$ & $29 / 03 / 08$ & $30 / 03 / 08$ & $05 / 04 / 08$ & $19 / 10 / 08$ & $25 / 10 / 08$ & $26 / 10 / 08$ & $01 / 11 / 08$ \\
$22 / 03 / 09$ & $28 / 03 / 09$ & $29 / 03 / 09$ & $04 / 04 / 09$ & $18 / 10 / 09$ & $24 / 10 / 09$ & $25 / 10 / 09$ & $31 / 10 / 09$ \\
$21 / 03 / 10$ & $27 / 03 / 10$ & $28 / 03 / 10$ & $03 / 04 / 10$ & $17 / 10 / 10$ & $23 / 10 / 10$ & $24 / 10 / 10$ & $30 / 10 / 10$ \\
$20 / 03 / 11$ & $26 / 03 / 11$ & $27 / 03 / 11$ & $02 / 04 / 11$ & $16 / 10 / 11$ & $22 / 10 / 11$ & $23 / 10 / 11$ & $29 / 10 / 11$ \\
$18 / 03 / 12$ & $24 / 03 / 12$ & $25 / 03 / 12$ & $31 / 03 / 12$ & $14 / 10 / 12$ & $20 / 10 / 12$ & $21 / 10 / 12$ & $27 / 10 / 12$ \\
$24 / 03 / 13$ & $30 / 03 / 13$ & $31 / 03 / 13$ & $06 / 04 / 13$ & $20 / 10 / 13$ & $26 / 10 / 13$ & $27 / 10 / 13$ & $02 / 11 / 13$ \\
$23 / 03 / 14$ & $29 / 03 / 14$ & $30 / 03 / 14$ & $05 / 04 / 14$ & $19 / 10 / 14$ & $25 / 10 / 14$ & $26 / 10 / 14$ & $01 / 11 / 14$ \\
$19 / 10 / 15$ & $24 / 10 / 15$ & $29 / 03 / 15$ & $04 / 04 / 15$ & $19 / 10 / 15$ & $24 / 10 / 15$ & $25 / 10 / 15$ & $01 / 11 / 15$ \\
\hline
\end{tabular}

Table 5 Dates for the start and end of summertime in the study years

For each clock change pair of weeks, the STATS19 dataset was searched to find collisions that occurred when the solar altitude was less than $-6^{\circ}$ (calculated using the NOAA method) and that if the collision had taken place the exact same time in the other paired week, the sun would have had an altitude greater than $0^{\circ}$. Similarly, collisions that happened when the sun was above the horizon (altitude greater than $0^{\circ}$ ) that would have had an altitude below $-6^{\circ}$ if they had taken place in the 
other week were identified. It should be noted that this approach means that the timing of each collision window will vary with location, day and year. Collisions in both the mornings and evenings of the relevant weeks were found. The conditions are summarised in Table 6.

\begin{tabular}{|c|c|c|c|c|c|}
\hline CODE & Season & Time of Day & Week & Light Condition & $\begin{array}{l}\text { Approx length of } \\
\text { window [min] }\end{array}$ \\
\hline SMB & \multirow{4}{*}{ Spring } & \multirow{2}{*}{ Morning } & Before & Light & \multirow{2}{*}{5} \\
\hline SMA & & & After & Dark & \\
\hline SEB & & \multirow{2}{*}{ Evening } & Before & Dark & \multirow{2}{*}{32} \\
\hline SEA & & & After & Light & \\
\hline AMB & \multirow{4}{*}{ Autumn } & \multirow{2}{*}{ Morning } & Before & Dark & \multirow{2}{*}{7} \\
\hline AMA & & & After & Light & \\
\hline AEB & & \multirow{2}{*}{ Evening } & Before & Light & \multirow{2}{*}{33} \\
\hline AEA & & & After & Dark & \\
\hline
\end{tabular}

Table 6 Summary of study periods (shaded cells denote dark periods)

For each of the time windows in Table 6 the STATS19 data set was searched and the collisions that happened during each of the periods were noted. A summary of these findings is given in Table 7.

\begin{tabular}{|c|c|c|c|c|c|}
\hline \multirow{2}{*}{ CODE } & \multirow{2}{*}{$\begin{array}{c}\text { Number of } \\
\text { Collisions }\end{array}$} & \multirow{2}{*}{$\begin{array}{c}\text { Number of } \\
\text { Vehicles Involved }\end{array}$} & $\begin{array}{c}|c| \\
\text { Vehicle } \\
\text { Occupants }\end{array}$ & \multirow{2}{*}{ Pedestrians } & \multirow{2}{*}{ Cyclists } \\
\hline SMB & 24 & 41 & 31 & 0 & 1 \\
\hline SMA & 26 & 52 & 27 & 2 & 5 \\
\hline SEB & 931 & 1678 & 895 & 220 & 120 \\
\hline SEA & 754 & 1322 & 702 & 179 & 121 \\
\hline AMB & 155 & 280 & 130 & 23 & 29 \\
\hline AMA & 124 & 222 & 110 & 20 & 17 \\
\hline AEB & 1493 & 2794 & 1407 & 302 & 240 \\
\hline AEA & 1745 & 3390 & 1676 & 415 & 256 \\
\hline
\end{tabular}

Table 7 Summary of collisions and their impacts

Note: in Table 7, the column "vehicle occupants" includes all casualties that are not pedestrians or cyclists, thus it includes motorcyclists, as well as passengers in buses.

It is possible that the change in the number of collisions that occurred during the week of the clock change occurred due to factors not associated with daylight. To study the extent to which other factors could be causing changes in the collision rates, control periods either side of dawn and dusk where the whole period in both weeks was either light or dark in all areas studied were counted. For each of the control periods the number of collisions, vehicles involved and casualties caused were counted. No breakdown of casualty type was conducted as these periods were only being used to provide an overall check to ensure other major factors were not influencing the results during the clock change periods. Table 8 shows the time of the control periods. 


\begin{tabular}{|c|ccc|cc|}
\hline Code & \multicolumn{3}{|c|}{ Condition } & \multicolumn{2}{c|}{ Times } \\
\cline { 5 - 6 } & & & Start & End \\
\hline SAD & Spring & AM & Dark & $04: 10$ & $05: 10$ \\
SAL & Spring & AM & Light & $07: 30$ & $08: 30$ \\
SPL & Spring & PM & Light & $16: 50$ & $17: 50$ \\
SPD & Spring & PM & Dark & $20: 50$ & $21: 50$ \\
AAD & Autumn & AM & Dark & $04: 50$ & $05: 50$ \\
AAL & Autumn & AM & Light & $08: 30$ & $09: 30$ \\
APL & Autumn & PM & Light & $14: 40$ & $15: 40$ \\
APD & Autumn & PM & Dark & $18: 40$ & $19: 40$ \\
\hline
\end{tabular}

Table 8 Times of the control periods

Table 9 gives the results of the control periods analysis.

\begin{tabular}{|c|c|c|c|c|c|c|}
\hline \multirow{3}{*}{ Code } & \multicolumn{3}{|c|}{ Before } & \multicolumn{3}{c|}{ After } \\
\cline { 2 - 7 } & No. of collisions & No. Vehicles & No. Casualties & No. of collisions & No. Vehicles & No. Casualties \\
\hline SAD & 161 & 255 & 214 & 204 & 305 & 286 \\
SAL & 2381 & 4601 & 3036 & 1923 & 3648 & 2396 \\
SPL & 2646 & 4937 & 3485 & 2967 & 5625 & 3975 \\
SPD & 1050 & 1827 & 1504 & 1131 & 1982 & 1662 \\
AAD & 281 & 473 & 346 & 312 & 502 & 390 \\
AAL & 2628 & 4933 & 3349 & 2533 & 4800 & 3257 \\
APL & 2753 & 5041 & 3659 & 2584 & 4730 & 3524 \\
APD & 2313 & 4311 & 3144 & 2245 & 4088 & 3040 \\
\hline
\end{tabular}

Table 9 Summary of the collisions during the control periods

\section{Discussion}

The study has investigated various methods to determine if collisions take place in the light or the dark and chosen to use solar altitude to determine light condition. The choice of solar altitude greater than $0^{\circ}$ for being light and less than $-6^{\circ}$ for being dark provides a simple way of selecting comparable collisions from either side of the biannual clock changes. This selection means that the study excludes collisions that occur during twilight. Twilight accidents have already been looked at by Ferguson et al; however, their sample probably included lots of collisions that happened in darkness. This does not mean that collisions during twilight are not important. The variable nature of light during this period means it is challenging to analyse this time window.

Comparing the number of collisions and casualties between all four sets of light and dark periods it is clear that there are more collisions during the dark periods. Table 10 shows the relative increases of various outcomes associated with the number of collisions for the whole period examined.

\begin{tabular}{|l|c|c|}
\hline Parameter & $\begin{array}{c}\text { Percentage increase in } \\
\text { the dark }\end{array}$ & $\begin{array}{c}\text { Percentage change } \\
\text { during corresponding } \\
\text { control periods }\end{array}$ \\
\hline Number of Collisions & $19.3 \%$ & $-6.8 \%$ \\
\hline Number of Vehicles Involved & $23.3 \%$ & $-8.0 \%$ \\
\hline Casualties: Vehicle Occupants & $21.2 \%$ & $*$ \\
\hline Casualties: Pedestrians & $31.7 \%$ & $*$ \\
\hline Casualties: Cyclists & $8.2 \%$ & $-7.3 \%$ \\
\hline Casualties: Total & $21.3 \%$ & $*$ \\
\hline \multicolumn{2}{|c|}{ The breakdown of casualty types was not calculated for the control periods } \\
\hline
\end{tabular}

Table 10 Increases in collisions and their outcomes during the dark periods 


\section{Conclusion}

This paper has made the case for the use of solar altitude at the time of a collision to determine if the incident took place in the light or the dark. Using the criteria proposed, the road traffic collision record for England, Scotland and Wales (2005 - 2015) has been examined for collisions taking place in the weeks either side of the spring and autumn clock change during weeks when the light condition at the time of the collision would be different if it was on the other side of the clock change. As expected, this revealed higher rates of collisions and injuries during the dark periods.

This initial review of collisions during equivalent light and dark periods demonstrates that the method works and further work studying the incidents in more detail is planned so that the cause of the additional night time collisions can be better understood.

\section{Acknowledgement}

This work was partly funded by EPSRC grant number EP/N509577/1

\footnotetext{
${ }^{1}$ CIE 093-1992, Road lighting as an accident countermeasure, ISBN: 9783900734305

${ }^{2}$ Ferguson, S.A., Preusser, D.F., Lund, A.K., Zador, P.L., Ulmer, R.G., 1995. Daylight saving time and motor vehicle crashes: the reduction in pedestrian and vehicle occupant fatalities. American Journal of Public Health

${ }^{3}$ PLG08 Guidance on the Application of Adaptive Lighting within the Public Realm, The Institution of Lighting Professionals, 2016

${ }^{4}$ Ferguson, S.A., Preusser, D.F., Lund, A.K., Zador, P.L., Ulmer, R.G., 1995. Daylight saving time and motor vehicle crashes: the reduction in pedestrian and vehicle occupant fatalities. American Journal of Public Health ${ }^{5}$ Uttley, J., Fotios, S. The effect of ambient light condition on road traffic collisions involving pedestrians on pedestrian
crossings. Accident Analysis and Prevention 108 (2017) 189-200

${ }^{6}$ Sullivan, J. M. and Flannagan, M. J. (2002). The role of ambient light level in fatal crashes: Inferences from daylight saving time transitions. Accident Analysis and Prevention 34 487-498.
} 
${ }^{7}$ Andre, J. and D. A. Owens (2001). The twilight envelope: A user-centered approach to describing roadway illumination at night. Human Factors 43(4): pp 620-630

${ }^{8}$ Road Safety Data, Department of Transport, available at https://data.gov.uk/dataset/cb7ae6f0-4be6-4935-9277$\underline{47 \text { e } 5 \text { ce } 24 \text { a11f/road-safety-data }}$

${ }^{9}$ National Oceanic \& Atmospheric Administration Earth System Research Laboratory, NOAA Solar Calculator. https://www.esrl.noaa.gov/gmd/grad/solcalc/ with downloadable spreadsheet version from https://www.esrl.noaa.gov/gmd/grad/solcalc/NOAA_Solar_Calculations_day.xls

${ }^{10}$ Public Health England Solar Monitoring Network. Available from: https://uk-air.defra.gov.uk/research/ozone-uv/uvuk-monitoring.

${ }^{11}$ Unwin, J, Symonds P and Laike, T. (2017) Does lighting affect pedestrian flows? A pilot study in Lund, Market Harborough and Dublin. Lux Europa 2017, European Lighting Conference. Ljubljana, Slovenia, September 18-20, 2017.

${ }^{12} \mathrm{~S}$ Fotios, J Uttley \& S Fox. A whole-year approach showing that ambient light level influences walking and cycling. Lighting Res. Technol. 2017; 0: 1-10 


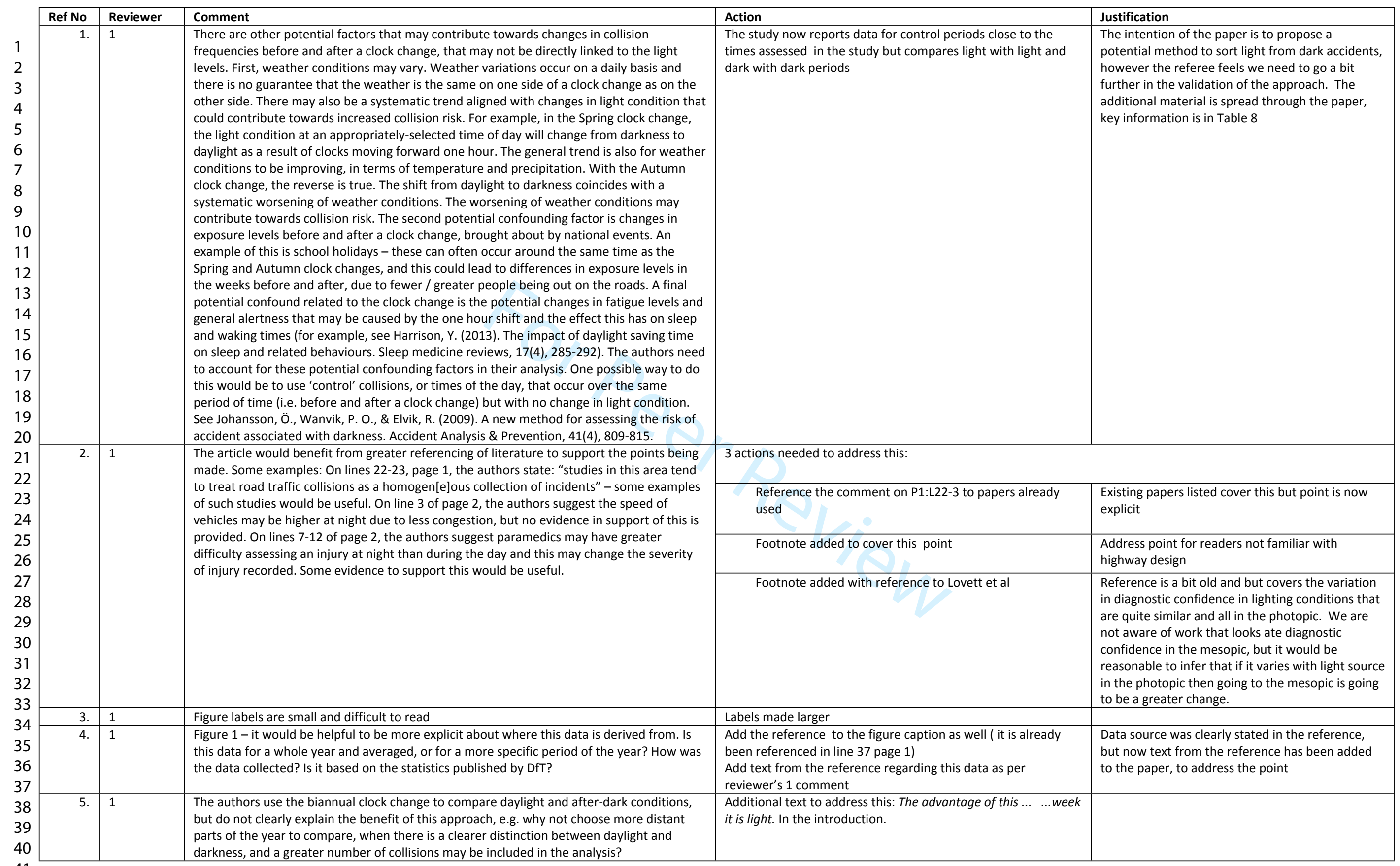




\begin{tabular}{|c|c|c|c|c|}
\hline Ref No & Reviewer & Comment & Action & Justification \\
\hline 6. & 1 & $\begin{array}{l}\text { Lines 6-8, page 3. The authors suggest the difference between am and pm seen in Figure } 2 \\
\text { may be due to police officers arriving at a collision scene sometime after the actual collision } \\
\text { occurred, and judging the light condition at that time rather than at the time of the } \\
\text { collision. This seems a reasonable explanation, but there may be other explanations too, } \\
\text { e.g. the perceived quality of the light at sunrise and sunset may be different, leading to } \\
\text { different interpretations of whether it is 'dark' or 'daylight'. E.g. refraction of light is } \\
\text { different at sunrise and sunset, Sampson, R. D., Lozowski, E. P., Peterson, A. E., \& Hube, D. } \\
\text { P. (2003). Variability in the astronomical refraction of the rising and setting Sun. } \\
\text { Publications of the Astronomical Society of the Pacific, 115(812), 1256. It would be } \\
\text { interesting to compare collisions that were attended by police and those that were not (this } \\
\text { is a variable within STATS19) - does this difference between am and pm disappear? }\end{array}$ & $\begin{array}{l}\text { The data on which figure } 2 \text { was based was expanded to cover all } \\
\text { collisions that happened with solar altitude in the range and } \\
\text { analysis was carried out to see the impact of Police Officer } \\
\text { attending the scene. } \\
\text { Figure } 2 \text { was updated and is now based on the } 253,755 \\
\text { collisions found. Comments about the analysis with regard to } \\
\text { officer attendance added to the text. } \\
\text { Text now includes the words potential explanation }\end{array}$ & $\begin{array}{l}\text { The referee clearly was not happy with this point } \\
\text { of our paper. To put the matter to rest we } \\
\text { calculated the solar altitude for all collisions in the } \\
\text { database and found } 253,755 \text { with solar altitude in } \\
\text { the range and all necessary fields filled. We } \\
\text { carried out analysis of the sample based on Police } \\
\text { attendance and generated a series of plots of } \\
\text { similar form to figure } 2 \text {. The changes between the } \\
\text { various charts were small, however, in the cases } \\
\text { where there was no police attendance there was } \\
\text { less difference between morning and afternoon } \\
\text { results. } \\
\text { This is a bit of a side issue for the paper so we } \\
\text { chose not to add all of the extra figures to the } \\
\text { paper }\end{array}$ \\
\hline 7. & 1 & $\begin{array}{l}\text { Lines } 38-41 \text { page } 3-\text { it would be helpful to have further explanation about the illuminance } \\
\text { recording at the sites described. E.g. are these sites located in rural or urban areas? How } \\
\text { many other sites are there and why were these } 8 \text { selected? }\end{array}$ & Text has been added to cover the location and choice of sites & $\begin{array}{l}\text { These locations were not selected from a list of } \\
\text { others, they are the only locations where England, } \\
\text { Scotland and Wales collect this data. Therefore all } \\
\text { the available information has been taken into } \\
\text { consideration. PHE does have sites in Ulster but } \\
\text { these were not used a STATS19 has no data from } \\
\text { there }\end{array}$ \\
\hline 8. & 1 & $\begin{array}{l}\text { Lines } 21-22 \text { page } 5 \text { - the authors state that comparisons of the illuminance measurements } \\
\text { across the } 8 \text { sites did not find any significant differences, but the results of any statistical } \\
\text { comparisons should be reported. It would also be useful to provide descriptive statistics } \\
\text { related to the illuminance measurements at the } 8 \text { sites - how much variation is there } \\
\text { between sites, and between different time-points? }\end{array}$ & \multicolumn{2}{|c|}{$\begin{array}{l}\text { A more detailed comparison of percentiles has been added to address this point. } \\
\text { The statistical analysis suggested has not been completed for the following reasons: } \\
\text { - A comparison of all illuminance values, across sites is not valid in this case, as the sites are in different geographical } \\
\text { locations, therefore expected to be different. The same applies to time points. } \\
\text { - Daylight data are not normally distributed, therefore means and variances are not appropriate in this case. } \\
\text { - Statistical methods used throughout the paper are descriptive rather than inferential (Bayesian). Bayesian statistical } \\
\text { methods do not apply because we are not making predictions based on analysis of the datasets. This would be } \\
\text { inappropriate because the datasets used are non-homogeneous. } \\
\text { - It could be argued that the percentile approach used to support the cut off decision, is more robust than the } 0.05 \\
\text { confidence interval often used in Bayesian statistics. This is because we are using the third percentile at the extremes } \\
\text { to explain the choice of cut off altitude. This is well within the five percentiles at either extremes, therefore the } \\
\text { approach employed is considered rigorous. }\end{array}$} \\
\hline 9. & 1 & Table 4 - the final dates for Spring Before are actually for Autumn Before & Error fixed & \\
\hline 10. & 1 & $\begin{array}{l}\text { Lines } 30-31 \text { page } 6 \text { - the authors state that collisions with solar altitudes below }-6 \text { degrees } \\
\text { were identified. However, it is not clear how the solar altitude at the time of each collision } \\
\text { was calculated - the solar altitude will vary as a function of time of day and longitude / } \\
\text { latitude, so using the same time window for all collisions, to identify the solar altitude at the } \\
\text { time of those collisions, may not be appropriate if that was done. }\end{array}$ & Text added to say that the NOAA method was used & $\begin{array}{l}\text { This should clarify the text, as the NOAA method } \\
\text { requires date, time, latitude and longitude }\end{array}$ \\
\hline 11. & 1 & Table 5 - final column, it would be useful to state what these time windows actually were & $\begin{array}{l}\text { Text added to explain this point It should be noted that this... } \\
\text {...day and year. }\end{array}$ & $\begin{array}{l}\text { It is not possible to give exact lengths of the } \\
\text { windows due to variations between locations, } \\
\text { years and days }\end{array}$ \\
\hline 12. & 1 & $\begin{array}{l}\text { Line } 56 \text { (page 7) - the Fotios et al analysis used a whole-year approach and will therefore } \\
\text { have included collisions that occurred greater than an hour before or after sunset (although } \\
\text { within the same hour of the day throughout the year). }\end{array}$ & Delete Fotios reference & $\begin{array}{l}\text { Simplest way to resolve the issue as an in depth } \\
\text { analysis of Fotios et al would take up a lot of space }\end{array}$ \\
\hline
\end{tabular}


